to show whether the rapid onset of passivity prevented a long enough period $(3-5 \mathrm{~min})$ for the initiation of convection.

Department of Chemistry,

$$
\text { R. N. O'Brien }
$$

University of Alberta, Edmonton.

${ }^{\wedge}$ O'Brien, R. N., and Rosenfield, C., Nature, 187, 935 (1960).

"Ibl, N., and Muller, R., Z. Elektrochem., 59, 671 (1955); J. Electrochem. Soc., 105, 346 (1958)

s'Brien, R. N., Yakymyshyn, W. F., and Leja, J., J. Electrochem. Soc., 105,346 (1958).

-Wilke, C. R., Eisenberg, M., and Tobias, C. W., J. Electrochem. Soc., 100 513 (1952).

\section{Inhibition of Corrosion of Magnesium in Chromic Acid}

Measurement of losses in weight due to corrosion of magnesium in $0.1 \mathrm{~N}$ sulphuric and chromic acids of $p \mathrm{H}$ 1.4 over a 4 -week period showed a loss of $3,800 \mathrm{mg} / \mathrm{dm}^{2}$ in sulphate and no loss in chromate.

Time-potential and oxide film thickness measurements indicated the oxide film to be more protective in the chromic acid solution:

\section{Electrode potential after $1 \mathrm{~h}$ in $0.1 \mathrm{~N}$ sulphuric acid-1.9 V Electrode potential after $1 \mathrm{~h}$ in $0.1 \mathrm{~N}$ chromic acid- $-0.8 \mathrm{~V}$ Film thickness after $1 \mathrm{~h}$ in $0 \cdot 1 \mathrm{~N}$ sulphuric acid, $3.0 \mathrm{~A}$ \\ Film thickness after $1 \mathrm{~h}$ in $0.1 \mathrm{~N}$ chromic acid, $14.0 \AA$}

After contact with magnesium oxide for $\mathrm{I} \mathrm{h}$, analysis showed 780 p.p.m. of magnesium had dissolved in the sulphuric acid solution and 2,600 p.p.m. were present in the chromic acid solution. However, analysis of solutions of acid which had been in contact with the oxide-covered metal for $1 \mathrm{~h}$ showed 840 p.p.m. of magnesium in the sulphate solution and 1 p.p.m. in the chromate solution. Analysis of the oxide film stripped from the magnesium specimen which had been immersed in the chromic acid solution showed 0.25 p.p.m. of chromium irroversibly absorbed from $200 \mathrm{ml}$. of solution on to $90 \mathrm{~cm}^{2}$ of specimen.

A possible explanation for the lowered oxidesolubility in the chromic acid solution (as compared with the solubility of massive $\mathrm{MgO}$ ) is that chromic ions are formed by electrochemical reduction of chromate at the magnesium surface, and cation exchange between magnesium from the oxide and chromic ions from solution occurs in preference to exchange between magnesium and hydrogen ions. However, the presence of chromate is also essential, as saturation of $0.1 \mathrm{~N}$ sulphuric acid with chromic sulphate does not inhibit corrosion of magnesium, and it is possible that complexing chromic ions with chromate or counterabsorption of chromate ions plays a part in lowering oxide solubility in chromate solutions.

The lowering of oxide solubility in chromic acid is considered a major factor in inhibiting corrosion of magnesium in chromic acid; a parallel series of results was obtained for zine in chromic acid, showing that the process of inhibition of corrosion of zine in this solution may be explained in a similar fashion.

Experiments on aluminium ${ }^{1}$ indicated that processes of initiation and inhibition of corrosion could be explained in terms of the initial rate of solution of the air-formed oxide film and the nature of the products formed at anodic areas.

The evidence obtained indicates that similar considerations apply to the corrosion behaviour of magnesium and zinc.

This communication is published by permission of the Chief Scientist, Department of Supply, Melbourne. K. F. LORKINe

Australian Defence Scientific Service,

A.eronautical Research Laboratory, Melbourne.

rLorking, K. F., and Mayne, J. E. O., J. App. Chem., 11, 170 (1861).

\section{BIOCHEMISTRY}

\section{A Standardized Technique for the Separation of Steroids by Thin-layer Chromatography}

THE thin-layer ehromatographic separation of steroids on silica-gel chromatoplates is a rapid and useful preparative and analytical technique ${ }^{1-4}$. However, the ascending organic solvent development of chromatoplates in an atmosphere of variable temperature and humidity produces streaking and poor resolution of C-19 and C-2I steroids. This communication describes a method which eliminates these difficulties.

Glass plates $20 \times 20 \times 0.4 \mathrm{~cm}$ are cleaned with deter. gent and successive washes each of running tap and distilled water. Thirty grams of silica gel (E. Merck, Darmstadt) per $60 \mathrm{ml}$. of distilled water are stirred vigorously by hand for $90 \mathrm{sec}$ and the slurry applied uniformly at $0.25 \mathrm{~mm}$ with a commercial spreading device (Desaga, Heidelberg). The coated plates are air-dried for $15 \mathrm{~min}$ at room temperature and then heated in an air oven for $60 \mathrm{~min}$ at $100^{\circ}-110^{\circ} \mathrm{C}$. The plates are cooled and stored in a desiccator containing silica gel indicating 6-16 mesh (Will Corporation, New York 52, New York) until used.

Five to ten micrograms of steroid dissolved in absolute methanol are applied with a microlitre syringe (Hamilton Co. Inc., Whittier, California) $2.0 \mathrm{~cm}$ from the lower edge of the plate. A straight lower edge of absorbent is removed $1.5 \mathrm{~cm}$ from the origin. A template facilitated the transfer of steroids to the starting line, starting $2.0 \mathrm{~cm}$ from each of the plate's side edges. The steroids are dried by an air blower.

A glass rectangular chamber $30.0 \times 6.7 \times 22.2 \mathrm{~cm}$ (Brinkmann Instruments Inc., Great Neck, New York). enclosed in a cardboard box, is equilibrated for at least $12 \mathrm{~h}$ before chromatographic development with 115-150 ml. of certified grade cyclohexane: redistilled ethyl acetate (1 : 1 by volume ${ }^{5}$ ). The glass top of the tank is sealed with high-vacuum grease (Dow Corning Corporation. Midland, Michigan), and the cover of the cardboard box closed during the chromatographic run. Ascending development is carried out for 90-105 min. Thin-layer chromatography is carried out in a room equipped with a constant temperature of $24^{\circ} \mathrm{C}$ and a relative humidity of 32-34 per cent.

At the conclusion of the run a straight line solvent front is observed, marked, and the plates are dried. The steroids

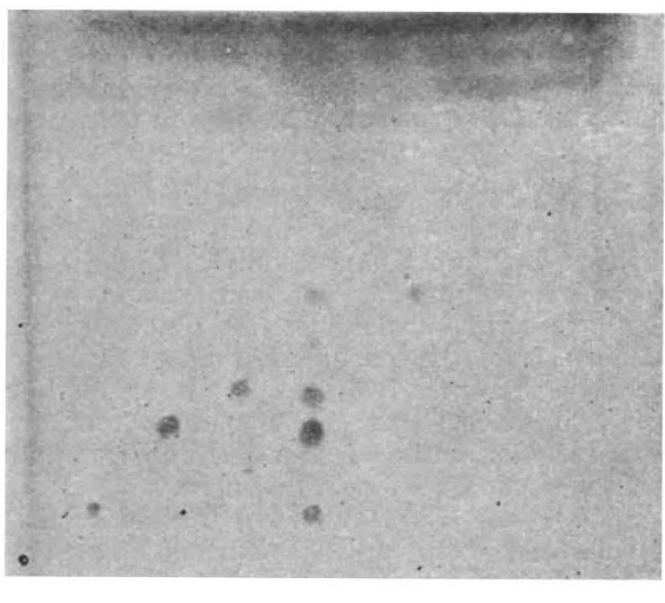

Fig. 1. Separation of $4^{4}-3$-ketone steroids on 'Silical Gel $G^{\text {' }}$, in cyclohexane/ethyl acetate $(1: 1)$ developed in $90 \mathrm{~min}$. The arrows indicat the origin. The numbers refer to the following compounds: 1, Cortiso $(5 \mu \mathrm{g}) ; 2,11$-deoxycertisol, compound $S(15 \mu \mathrm{g}) ; 3,11 \beta$-hydroxyandrostenedione $(15 \mu \mathrm{g}) ; 4$, mixture; 5, progesterone $(10 \mu \mathrm{g}) ; 6,17 \alpha$ hydroxyprogesterone $(10 \mu \mathrm{g}) ; 7$, testosterone $(6 \mu \mathrm{g})$ 